\title{
Quantitative Peripheral Angiography
}

National Cancer Institute

\section{Source}

National Cancer Institute. Quantitative Peripheral Angiography. NCI Thesaurus. Code C120702.

A type of angiographic procedure that allows for direct quantitative assessment of the vessels of the hands, arms, feet and legs. 